\title{
Obtenção de compósitos cerâmico contendo resíduo de gesso, argilito e argila proveniente da extração de gipsita em Araripina no semiárido pernambucano
}

\author{
Pâmela Bento Cipriano ${ }^{a^{*}}$, Ana Vitória Freire Neves ${ }^{\mathrm{b}}$, Andréa de Vasconcelos Ferraz $^{\mathrm{a}}$ \\ ${ }^{a}$ Instituto de Pesquisa em Ciência dos Materiais - IPCM \\ ${ }^{b}$ Colegiado de Engenharia Agrícola e Ambiental - CENAMB \\ Universidade Federal do Vale do São Francisco (UNIVASF), Juazeiro, Bahia, Brasil \\ *e-mail: pamela.ufcg@gmail.com
}

\begin{abstract}
Resumo
Uma alternativa para buscar o desenvolvimento regional e aumento da competitividade do Polo Gesseiro do Araripe, está relacionada à pesquisa dos recursos locais. $\mathrm{O}$ trabalho visa à produção de compósitos cerâmicos utilizando argila residual (C) e argilito (A) gerados em grandes volumes durante a extração da gipsita e resíduo de gesso (G) obtido da fabricação de placas. Foram incorporados 40 e $50 \%$ de argilito e teores de 5 e $10 \%$ de resíduo de gesso. Melhores resultados foram obtidos nos compósitos contendo argilito e 5\% de resíduo de gesso sinterizados a $1050^{\circ} \mathrm{C}$. Os resíduos apresentaram um elevado potencial para ser usado como matérias-primas de menor custo, além de contribuir com a redução do impacto ambiental na região.
\end{abstract}

Palavras-chave: argila, Araripina, argilito, gipsita.

\section{INTRODUÇÃO}

A extração do minério gipsita $\left(\mathrm{CaSO}_{4} \cdot 2 \mathrm{H}_{2} \mathrm{O}\right)$ ocorre em nove estados brasileiros, no entanto as principais jazidas pertencem à região do Polo Gesseiro do Araripe em Pernambuco, abrangendo principalmente as cidades de Araripina, Trindade, Ouricuri, Ipubi e Bodocó. Uma das principais características da gipsita extraída do Araripe é o seu elevado teor de pureza ( $88 \%$ a $98 \%$ ), e quando calcinada perde cerca de 1,5 moléculas de água, transformando-se em gesso $\left(\mathrm{CaSO}_{4} \cdot \frac{1}{2} \mathrm{H}_{2} \mathrm{O}\right)$, muito utilizado principalmente em aplicações na área de construção civil (Oliveira e Shinohara, 2014).

Segundo dados do Anuário Mineral do Estado de Pernambuco a produção de gipsita bruta foi de 2.115.996 toneladas em 2016 representando uma importância econômica para o Estado, no entanto essa atividade gera grandes quantidades de resíduos, durante a extração do minério e na fabricação dos seus produtos. Esses resíduos causam grandes impactos na sustentabilidade do meio ambiente e o desafio é realizar o seu aproveitamento. Estudo mostrou como alternativa para minimizar os impactos ambientais a incorporação de $5 \%$ de resíduo de gipsita em massa de cerâmica vermelha, foram produzidos corpos de prova prensados e em seguida sinterizados a 1200 e $1250^{\circ} \mathrm{C}$. Os resultados mostraram uma absorção de água adequada a um material de grés, enquanto que o comportamento mecânico não atingiu o valor mínimo de 32 MPa (Lima et al., 2016).

O município de Araripina fica localizado a $683,8 \mathrm{~km}$ da capital, nesse local os resíduos minerais gerados após a extração da gipsita são formados basicamente por camadas de argila ou argilito que compõem o capeamento estéril ou minério de baixo teor que são considerados como minerais de baixo valor econômico na jazida, esses materiais são motivos de problemas, pois é necessário movimentar cada vez mais material para obtenção do minério, logo estudos tem buscado o avanço tecnológico para o aproveitamento desse resíduo buscando o desenvolvimento regional (Bastos, 2013).

Estudo realizado com o material argiloso retirado da extração de gipsita coletado em uma mineradora localizada no município de Araripina utilizou a argila e teores de 5 e 10\% de resíduo de gesso para produção de produtos de cerâmica vermelha. Os melhores resultados foram obtidos com a adição de $5 \%$ de resíduo de gesso nas amostras queimadas a $800^{\circ} \mathrm{C}$ apresentando propriedades semelhantes à argila pura. A utilização de materiais residuais permite a redução dos impactos ambientais e a possibilidade de novas formulações para produtos de cerâmica vermelha (Cipriano; Rezende; Ferraz, 2019).

$\mathrm{O}$ argilito é uma rocha de origem sedimentar de grãos finos e laminados, contendo feldspato, quartzo, argilominerais e clorita, a sua composição química e mineralógica é similar às das argilas podendo atuar como um inerte durante a secagem e apresenta, durante a queima, comportamento físico-químico similar ao da argila (Candido, 2012). Estudos mostraram propriedades adequadas em aplicações do argilito em formulações para fabricação de telhas (Vieira; Emiliano, 2013; Vieira; Pinheiro, 2013). Foi desenvolvida uma massa cerâmica contendo argilas cauliníticas, chamote e argilito para a obtenção de pavimento intertravado tipo adoquim. Os resultados indicaram que a adição de $50 \%$ de argilito diminuiu 
a absorção de água e a retração dos corpos de prova, enquanto o chamote não alterou de forma significativa as propriedades (Candido et al., 2013). O argilito de Santa Gertrudes-SP apresentou resultados satisfatórios na substituição de feldspato potássico em formulações para produção de porcelanato. Este proporcionou a gresificação em temperaturas menores, redução na absorção de água e maior resistência mecânica e deformação piroplástica (Hoffmann; Santos; Morelli, 2012).

Neste contexto, este trabalho avaliou a incorporação de 40 e $50 \%$ de argilito em corpo de prova contendo 5 e $10 \%$ de resíduos de gesso proveniente da indústria de placas e argila residual obtida durante a extração da gipsita para produção de compósitos buscando viabilizar a utilização desses materiais como alternativa para aplicação na indústria de cerâmica vermelha. Foram avaliados o efeito do teor de resíduo de gesso e argilito adicionados nas propriedades físicas e mecânicas das amostras, visando agregar valor a esses materiais de baixo custo e reduzir a quantidade de resíduos descartados no meio ambiente.

\section{MATERIAIS E MÉTODOS}

Os materiais residuais utilizados foram: argilito (A), argila (C) e resíduo de gesso (G). O argilito e a argila foram obtidos na etapa de extração da gipsita e fornecidos pela Ecogesso Indústria e Comércio LTDA, no município de Araripina-PE. O resíduo de gesso foi coletado em uma empresa de produção de placas em Juazeiro-Ba.

A argila foi seca em estufa à temperatura de $60^{\circ} \mathrm{C}$ durante 24 h. Em seguida, a homogeneização e a desagregação da amostra foram realizadas manualmente em um almofariz. Enquanto que o argilito e o resíduo de gesso foram submetidos à moagem em um moinho de bolas (Pavitest).

$\mathrm{O}$ teor de umidade da argila e do argilito in natura foi determinado de acordo com a norma NBR 6457 (1986). A composição química da argila e do argilito foram obtidos através da espectroscopia dispersiva de energia (EDS) em um equipamento Oxford (X-act) acoplado ao microscópio eletrônico de varredura e complementada pela análise química para determinação dos elementos (Cu, Fe, Mn, Zn), matéria orgânica, capacidade de troca de cátions (CTC) e pH.

A morfologia da argila e do argilito in natura foi analisada por microscopia ótica em um estereoscópio da marca Marte usando luz refletida e através da microscopia eletrônica de varredura em um microscópio (Tescan, modelo Vega 3XMU) com magnificações de 10.000×. As amostras foram recobertas com ouro durante $10 \mathrm{~min}$ com uma corrente de $15 \mathrm{~mA} \cdot 5 \mathrm{~min}^{-1}$, utilizando um equipamento Quorum (Q150R ES).

Para a confecção dos corpos de prova as matérias-primas foram utilizadas nas granulometrias: passante na peneira $\mathrm{ABNT} \mathrm{N}^{\circ} 80$ para a argila, na peneira $A B N T N^{\circ} 100$ para o resíduo de gesso e na peneira $\mathrm{ABNT} \mathrm{N}^{\mathrm{o}} 16$ para o argilito. Foi adicionado $10 \%$ de água destilada no preparo da massa para a conformação dos corpos de prova por prensagem uniaxial em forma de barras retangulares de
$60 \times 20 \times 5 \mathrm{~mm}^{3}$, em molde de aço sob pressão de $20 \mathrm{MPa}$. A Tabela 1 mostra as composições dos corpos de prova.

Os corpos de prova preparados com argila contendo 40 e $50 \%$ de argilito, e adicionados 5 e $10 \%$ de resíduo de gesso, foram secos em estufa a $110^{\circ} \mathrm{C}$ por $24 \mathrm{~h}$ e sinterizados em forno do tipo mufla a 800 e $1050^{\circ} \mathrm{C}$ durante 2 h. Após a queima, os corpos de prova foram submetidos às seguintes caracterizações: a densidade aparente a seco, a porosidade, a absorção total de água, a perda ao fogo, a retração linear de queima, tensão de ruptura à flexão em três pontos e a superfície de fratura foi avaliada por microscopia eletrônica de varredura com magnificação de $8.000 x$.

\section{RESULTADOS E DISCUSSÃO}

A Tabela 2 apresenta os teores de umidade obtidos da argila e do argilito conforme recebido. A amostra A apresentou um menor teor de umidade devido à sua característica de rocha. Enquanto que na amostra $\mathrm{C}$ observou-se um teor médio de $13 \%$, característico de materiais argilosos, pois a retenção de umidade do solo sofre interferência da quantidade de argilominerais presentes na composição mineralógica (Mile e Mitkova, 2012).

A Tabela 3 apresenta a composição química elementar média da argila e do argilito analisadas por EDS. As composições químicas, mineralógicas e a textura das argilas vermelhas interferem nas propriedades do produto final, logo o conhecimento dessas caracteristicas é importante para aumentar a qualidade e diminuir os defeitos das peças acabadas, além de reduzir a perda de matéria-prima (Hettiarachchi; Motha; Pitawala, 2010). As amostras apresentam os elementos prioritários oxigênio, sílicio, alumínio, ferro e potássio em teores semelhantes. Nas argilas geralmente o silício esta associado à sílica podendo estar na forma livre, como quartzo, ou combinada com a alumina para formar os aluminossilicatos. Os compostos de ferro estão predominantemente presentes nas argilas na forma de hidróxidos. O potássio na forma de óxido tem a função de fundente agindo na formação de fase líquida importante durante a etapa de densificação do

Tabela 1. Composições dos corpos de prova.

\begin{tabular}{cccc}
\hline Amostra & C (\%) & A (\%) & G (\%) \\
\hline CA40 & 60 & 40 & 0 \\
CA50 & 50 & 50 & 0 \\
CA40G5 & 55 & 40 & 5 \\
CA40G10 & 40 & 40 & 10 \\
CA50G5 & 45 & 50 & 5 \\
CA50G10 & 40 & 50 & 10 \\
\hline
\end{tabular}

*C - argila, A - argilito e $\mathrm{G}$ - resíduo de gesso

Tabela 2. Teor de umidade da argila e do argilito.

\begin{tabular}{cc}
\hline Amostra & Teor de umidade (\%) \\
\hline A & $8,40 \pm 0,27$ \\
C & $13,30 \pm 0,04$ \\
\hline
\end{tabular}


corpo cerâmico que ocorre na sinterização (Souza; Vieira; Monteiro, 2008).

A Tabela 4 apresenta a análise química das amostras obtidas por métodos químicos. Os resultados complementam a análise semi-quantitativa realizada por EDS. Foi observado $\mathrm{pH}$ ácido nas amostras. A maior quantidade de matéria orgânica foi da amostra C. Os elementos (Cu, Mn e Zn) complementam a composição química das amostras. Quanto maior a capacidade de troca de cátions (CTC) maior será a facilidade de reações desses cátions com o meio. A capacidade de troca cationnica é uma propriedade importante das argilas, pois pela troca de cátions pode-se modificá-las quimicamente interferindo diretamente sobre suas propriedades físico-químicas e possíveis aplicações tecnológicas (Teixeira-Neto e Teixeira-Neto, 2009).

A Figura 1 apresenta as micrografias dos resíduos de argilito e argila. As características dos materiais naturais que contém argila dependem dos locais de origem e das condições em que se formaram, pois a composição dos argilominerais pode variar (Teixeira-Neto e Teixeira-Neto, 2009). A amostra A apresenta uma coloração cinza e estrutura em forma de lâminas paralelas e a amostra da argila C apresenta uma coloração avermelhada sem a presença de restos vegetais sugerindo ser uma camada uma camada mais interna em relação à superfície.
A Figura 2 apresenta as micrografias referentes às amostras de argila e argilito in natura. Observou-se nas micrografias a presença de pequenos aglomerados com textura característica das argilas e presença possivelmente de grãos de quartzo (Vieira e Monteiro, 2003). As composições mineralógica e química dos solos apresentam influência na dispersão da argila (Vitorino et al., 2003). Resultados semelhantes obtidos na literatura corroboram com as características dos materiais estudados devido à provável resistência para dispersar dos materiais argilosos, pois os microagregados de alta estabilidade formados na presença de agentes cimentantes como matéria orgânica e óxidos de ferro e alumínio, geralmente não fragmentam durante as etapas de desaglomeração e as partículas possuem um diâmetro correspondente ao das frações silte ou areia (Corá; Fernandes; Garrido, 2009).

A Tabela 5 mostra a retração linear de queima e a perda ao fogo das amostras sinterizadas a 800 e $1050^{\circ} \mathrm{C}$. Foi observada em todas as amostras uma maior retração linear com o aumento da temperatura de queima, esse comportamento era esperado e indica uma melhor sinterização dos corpos de prova em temperaturas maiores (Gaspareto e Teixeira, 2017). Logo, ocorreu uma melhor densificação dos corpos de prova reduzindo a porosidade e a absorção de água. $\mathrm{O}$ aumento na retração foi mais significativo com a incorporação do resíduo de gesso

Tabela 3. Resultado semi-quantitativo dos elementos presentes analisados por EDS.

\begin{tabular}{|c|c|c|c|c|c|c|c|c|c|c|c|}
\hline \multirow{2}{*}{ Amostra } & \multicolumn{11}{|c|}{ Teores de elementos presentes (\% em massa) } \\
\hline & $\mathbf{O}$ & Si & Al & $\mathrm{Fe}$ & $\mathbf{K}$ & Mg & $\mathbf{P b}$ & $\mathbf{B a}$ & Co & $\mathbf{N i}$ & Tl \\
\hline A & 52,9 & 22,2 & 10,4 & 4,0 & 1,8 & 1,1 & 0,5 & 0,3 & 0,1 & 0,1 & 0,3 \\
\hline $\mathrm{C}$ & 58,5 & 26,6 & 9,0 & 4,6 & 1,3 & & & & & & \\
\hline
\end{tabular}

Tabela 4. Análise química do argilito e da argila.

\begin{tabular}{|c|c|c|c|c|c|c|c|}
\hline Amostra & $\mathrm{pH}\left(\mathrm{H}_{2} \mathrm{O}\right)$ & $\begin{array}{c}\text { Matéria } \\
\text { orgânica } \\
\left(\mathbf{g} \cdot \mathbf{k g}^{-1}\right)\end{array}$ & 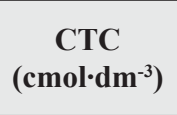 & $\begin{array}{c}\mathrm{Cu} \\
\left(\mathbf{m g} \cdot \mathbf{d m}^{-3)}\right.\end{array}$ & $\begin{array}{c}\mathrm{Fe} \\
\left(\mathrm{mg} \cdot \mathrm{dm}^{-3}\right)\end{array}$ & $\begin{array}{c}\text { Mn } \\
\left(\mathbf{m g} \cdot \mathrm{dm}^{-3}\right)\end{array}$ & $\begin{array}{c}\mathrm{Zn} \\
\left(\mathbf{m g} \cdot \mathbf{d m}^{-3}\right)\end{array}$ \\
\hline A & 5,90 & 2,60 & 16,42 & 3,10 & 46,60 & 28,30 & 23,80 \\
\hline $\mathrm{C}$ & 6,3 & 9,30 & 20,77 & 8,10 & 196,00 & 31,00 & 7,50 \\
\hline
\end{tabular}

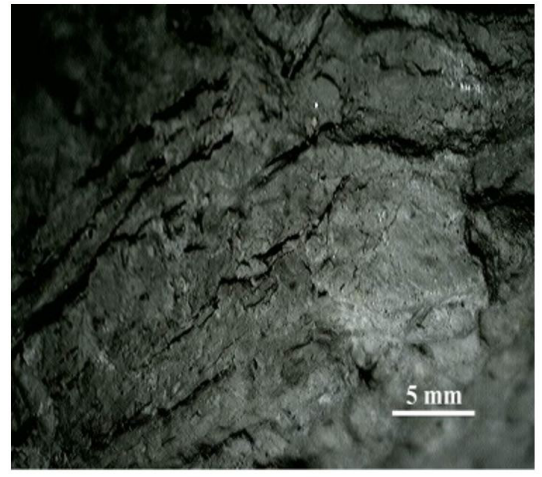

(a)

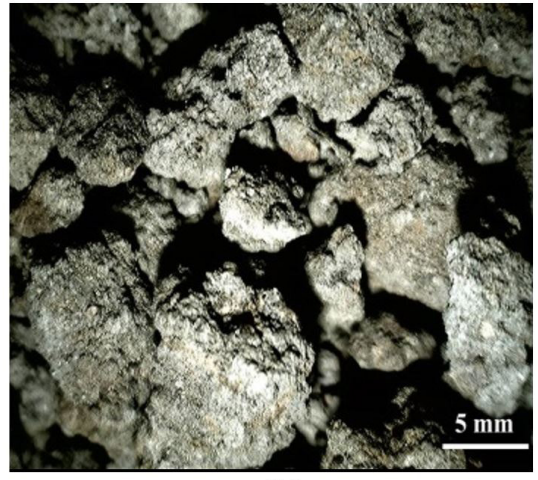

(b)

Figura 1. Micrografias obtidas por microscopia ótica das amostras in natura com magnificação de 20x: a) argilito (A) e b) argila (C). 
Tabela 5. Retração linear de queima e perda ao fogo dos corpos de prova sinterizados.

\begin{tabular}{cccccc}
\hline \multirow{2}{*}{ Amostra } & \multicolumn{2}{c}{ Retração linear de queima $(\mathbf{\%})$} & & \multicolumn{2}{c}{ Perda ao fogo $(\mathbf{\%})$} \\
\cline { 2 - 3 } \cline { 5 - 6 } & $\mathbf{8 0 0}\left({ }^{\circ} \mathbf{C}\right)$ & $\mathbf{1 0 5 0}\left({ }^{\circ} \mathbf{C}\right)$ & & $\mathbf{8 0 0}\left({ }^{\circ} \mathbf{C}\right)$ & $\mathbf{1 0 5 0}\left({ }^{\circ} \mathbf{C}\right)$ \\
\hline CA40 & $0,69 \pm 0,41$ & $1,50 \pm 0,24$ & & $8,83 \pm 0,18$ & $12,96 \pm 0,15$ \\
CA50 & $0,58 \pm 0,40$ & $1,45 \pm 0,41$ & & $9,05 \pm 0,17$ & $13,43 \pm 0,06$ \\
CA40G5 & $0,97 \pm 0,28$ & $3,68 \pm 0,22$ & & $12,25 \pm 0,73$ & $10,93 \pm 0,21$ \\
CA40G10 & $0,88 \pm 0,24$ & $3,05 \pm 0,27$ & & $12,48 \pm 0,38$ & $13,07 \pm 0,39$ \\
CA50G5 & $1,02 \pm 0,35$ & $4,13 \pm 0,43$ & & $12,72 \pm 0,28$ & $11,19 \pm 0,25$ \\
CA50G10 & $1,37 \pm 0,27$ & $4,01 \pm 0,39$ & & $12,79 \pm 0,42$ & $12,76 \pm 0,19$ \\
\hline
\end{tabular}

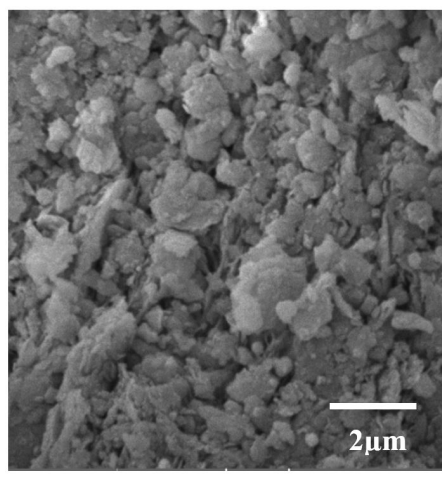

(a)

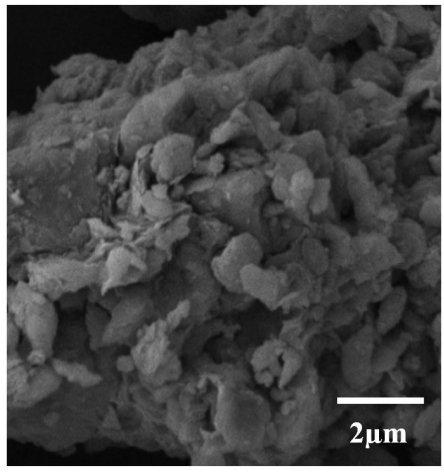

(b)

Figura 2. Micrografias obtidas por microscopia eletrônica de varredura do argilito e da argila in natura com aumento de $10.000 \times$ : a) A; b) C.
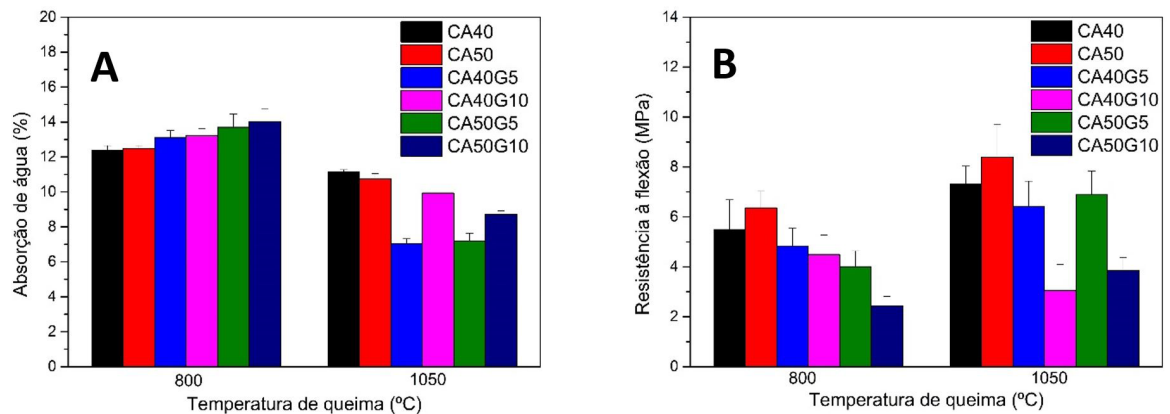

Figura 3. Propriedades das amostras sinterizadas a 800 e $1050^{\circ} \mathrm{C}$ : a) Absorção de água e b) Resistência à flexão.

independente da temperatura quando comparado com as formulações contendo apenas argilito.

A perda ao fogo foi maior com a adição de gesso quando comparado com as composições com o argilito na temperatura de $800^{\circ} \mathrm{C}$ independente do teor de gesso. Os corpos de prova sinterizados a $1050^{\circ} \mathrm{C}$ não apresentaram uma influência significativa no comportamento devido à composição. A perda ao fogo representa a perda de massa em relação à temperatura de queima atribuído principalmente pela liberação das águas presentes nos argilominerais, das transformações químicas e físicas que ocorrem no material durante a sinterização e da decomposição de compostos voláteis como matéria orgânica, carbonatos, sulfetos e sulfatos (Dutra et al., 2008).

A Tabela 6 apresenta a porosidade e a densidade aparente a seco dos corpos de prova sinterizados. Em $800^{\circ} \mathrm{C}$ a porosidade dos corpos cerâmicos aumenta com a incorporação do gesso, bem como a retração linear e a absorção de água. Enquanto que a $1050^{\circ} \mathrm{C}$ a porosidade diminui com a adição de gesso nas composições, a retração aumenta e a absorção não mostra uma tendência clara de comportamento.

A incorporação de gesso pouco influenciou a densidade aparente a seco provavelmente devido ao pequeno teor adicionado. Observou-se uma densidade aparente em média de $2 \mathrm{~g} \cdot \mathrm{cm}^{-3}$ em todas as composições estudadas. Quando a temperatura de queima aumentou de 800 para $1050^{\circ} \mathrm{C}$ a porosidade diminuiu indicando uma melhor sinterização na temperatura de $1050^{\circ} \mathrm{C}$. Essa redução foi mais significativa com a incorporação de gesso nas formulações.

A Figura 3 mostra a absorção de água e a resistência à flexão obtida nos corpos de prova sinterizados. Nos corpos de prova sinterizados a $800^{\circ} \mathrm{C}$ a absorção de água não 


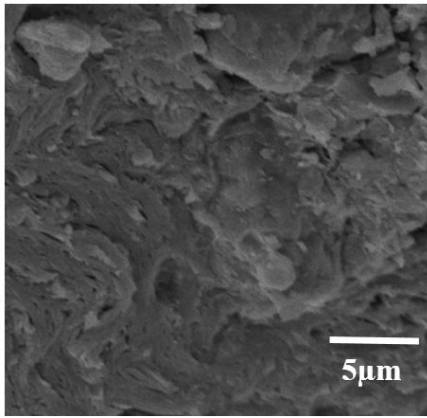

(a)

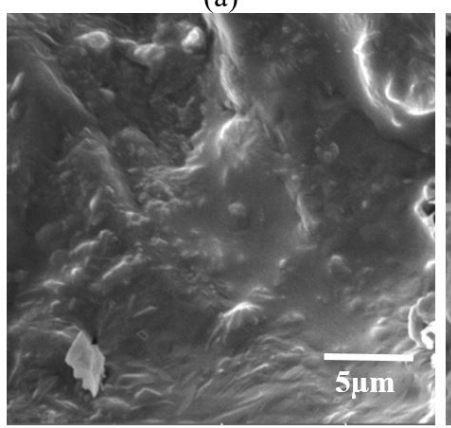

(d)

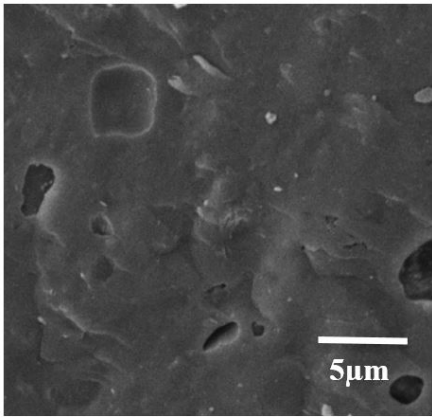

(b)

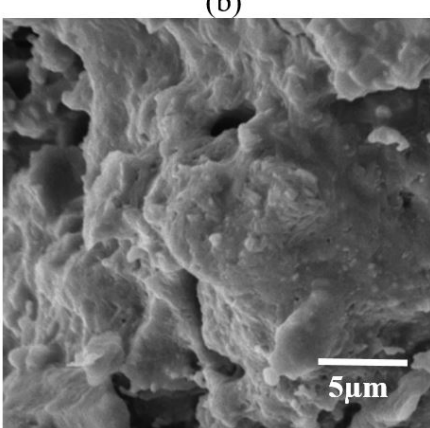

(e)

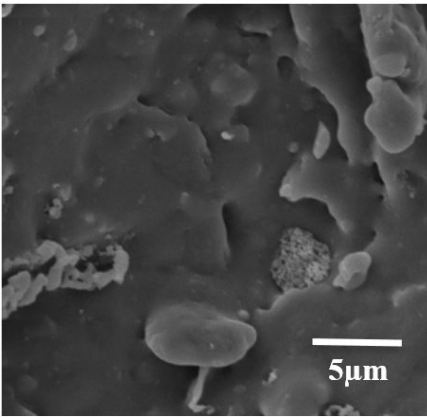

(c)

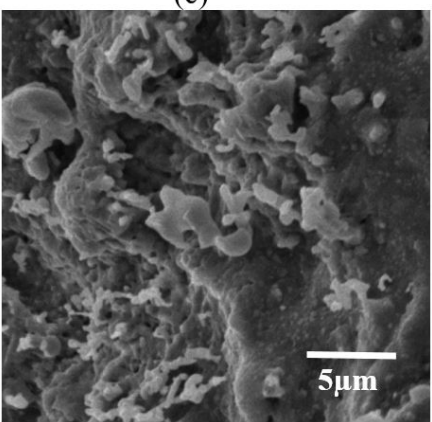

(f)

Figura 4. Micrografias da superfície de fratura das amostras sinterizadas a $1050^{\circ} \mathrm{C}$ : a) CA40, b) CA50, c) CA4OG5, d) CA40G10, e) CA50G5 e f) CA50G10.

Tabela 6. Porosidade e densidade aparente a seco dos corpos de prova sinterizados

\begin{tabular}{cccc}
\hline \multirow{2}{*}{ Amostra } & \multicolumn{2}{c}{ Porosidade (\%) } & $\begin{array}{c}\text { Densidade aparente a } \\
\mathbf{s e c o}\left(\mathbf{g} \cdot \mathbf{c m}^{-3}\right)\end{array}$ \\
\cline { 2 - 3 } & $\mathbf{8 0 0}\left({ }^{\mathbf{}} \mathbf{C}\right)$ & $\mathbf{1 0 5 0}\left({ }^{\mathbf{o}} \mathbf{C}\right)$ & $2,13 \pm 0,02$ \\
\hline CA40 & $12,39 \pm 0,26$ & $11,16 \pm 0,12$ & $2,10 \pm 0,04$ \\
CA50 & $12,49 \pm 0,16$ & $10,74 \pm 0,30$ & $2,12 \pm 0,05$ \\
CA40G5 & $13,10 \pm 0,41$ & $7,03 \pm 0,29$ & $2,15 \pm 0,15$ \\
CA40G10 & $13,22 \pm 0,41$ & $9,93 \pm 0,15$ & $2,08 \pm 0,03$ \\
CA50G5 & $13,68 \pm 0,77$ & $7,19 \pm 0,45$ & $2,05 \pm 0,03$ \\
\hline CA50G10 & $14,03 \pm 0,71$ & $8,71 \pm 0,20$ & \\
\hline
\end{tabular}

foi influenciada de forma significativa em relação às composições, enquanto que a $1050^{\circ} \mathrm{C}$ as amostras contendo 40 e $50 \%$ de argilito e $5 \%$ de resíduo de gesso apresentaram uma redução na absorção em relação às demais composições. A absorção de água com a adição de $10 \%$ de resíduo de gesso na temperatura de $1050^{\circ} \mathrm{C}$ foi semelhante às formulações apenas com argilito. Resultados semelhantes para absorção de água em torno de $7 \%$ em amostras contendo $5 \%$ de gesso sinterizadas a $1050^{\circ} \mathrm{C}$ foram reportados na literatura para aplicação em telhas no Estado do Piauí (Monteiro; Nascimento; Martinelli, 2009).

$\mathrm{O}$ incremento da temperatura proporciona uma maior resistência mecânica devido aos mecanismos de sinterização que aumenta a densificação dos corpos cerâmicos. De maneira geral a resistência à flexão reduziu com a incorporação de gesso independente da temperatura de queima. Na temperatura de $800^{\circ} \mathrm{C}$ as composições apresentaram resultados semelhantes com exceção do compósito contendo $50 \%$ de argilito e 10\% de resíduo de gesso.

Nas amostras que foram incorporadas o resíduo de gesso tanto com 40 e $50 \%$ de argilito na temperatura de $1050^{\circ} \mathrm{C}$, a adição de $5 \%$ de resíduo de gesso possibilitou maiores resistência mecânica e menor absorção de água quando comparado ao teor de $10 \%$. Esse comportamento era esperado visto que uma menor absorção de água pode estar relacionada com um melhor o empacotamento das partículas após a conformação indicando que o teor de 5\% de resíduo de gesso pode favorecer esse comportamento ou com a redução da porosidade devido à sinterização do material proporcionando uma maior resistência mecânica. Em estudo realizado pelo grupo de pesquisa utilizando as mesmas matérias-primas em compósitos contendo $5 \%$ de resíduo de gesso sinterizado a $1050^{\circ} \mathrm{C}$ foi reportado uma média de 2,8 MPa de resistência à flexão (Cipriano; Rezende; Ferraz, 2019). Logo, a presença do argilito 
nesses compósitos proporcionou melhorias importantes no comportamento mecânico para aplicações cerâmicas.

A Figura 4 apresenta as micrografias das superfícies de fratura das amostras sinterizadas a $1050^{\circ} \mathrm{C}$. As amostras com apenas argilito (CA40 e CA50) apresentaram poucos poros e regiões bem densificadas. A incorporação de 5\% de resíduo de gesso nas amostras indicou uma melhor sinterização com a redução dos defeitos e da porosidade na estrutura em relação a 10\% de gesso. Estas características microestruturais contribuí com os resultados da resistência mecânica (Figura 3).

\section{CONCLUSÕES}

Os principais elementos presente no argilito e na argila forma sílicio, alumínio, ferro e potássio em teores semelhantes. Os compósitos contendo argilito e 5\% de gesso sinterizados a $1050^{\circ} \mathrm{C}$ apresentaram uma redução na absorção de água e aumentou a resitência à flexão em relação ao teor de $10 \%$ de resíduo de gesso. A argila residual, o argilito e o resíduo de gesso são materiais potenciais para serem utilizados como matérias-primas de baixo custo e contribui para redução dos impactos ambientais gerados na cadeia produtiva da gipsita.

\section{AGRADECIMENTOS}

A CAPES, pela concessão da bolsa de pós-doutorado (PNPD). A Ecogesso pela doação dos materiais residuais: argila e argilito.

\section{REFERÊNCIAS}

Associação Brasileira de Normas Técnicas - ABNT NBR 6457: Amostras de solo - Preparação para ensaio de compactação e ensaios de caracterização (Determinação do teor de umidade de solos), Rio de Janeiro, RJ (1986).

BASTOS, F. F. Dissertação de Mestrado, Centro de Tecnologia e Geociência, Universidade Federal de Pernambuco, Recife - PE, 2013.

CANDIDO, V. S. Dissertação de Mestrado, Centro de Ciência e Tecnologia, Universidade Estadual do Norte Fluminense, Campos dos Goytacazes - RJ, 2012.

CANDIDO, V. S.; PINHEIRO, R. M.; MONTEIRO, S. N.; VIEIRA, C. M. F. Desenvolvimento de adoquim cerâmico com argilas cauliníticas, chamote e argilito. Cerâmica, v. 59, p. 310-316, 2013.

CIPRIANO, P. B.; REZENDE, R. T. O. DE; FERRAZ, A. DE V. Produção de cerâmica vermelha utilizando argila da mineração de gipsita e resíduo de gesso. Acta Brasiliensis, v. 3, n. 1, p. 25-29, 2019.

CORÁ, J. E.; FERNANDES, C.; GARRIDO, J. M. Adição de areia para dispersão de solos na análise granulométrica. Revista Brasileira de Ciência do Solo, v. 33, n. 1, p. 255-262, 2009.

DUTRA, R. P. S.; SILVA, J. B.; VARELA, M. L.; NASCIMENTO, R. M.; GOMES, U. U.; PASKOCIMAS, C. A. Avaliação da potencialidade de argilas do rio grande do norte, brasil. parte-II: propriedades tecnológicas. Cerâmica Industrial, v. 13, p. 47-50, 2008.

GASPARETO, M. G. T.; TEIXEIRA, S. R. Utilização de resíduo de construção civil e demolição (RCD) como material não plástico para a produção de tijolos cerâmicos. Cerâmica Industrial, v. 22, n. 2, p. 40-46, 2017.

HETTIARACHCHI, P.; MOTHA, J. T. S.; PITAWALA, H. M. T. G. A. Identification of an appropriate body composition for red clay products. Cerâmica, v. 56, p. 285-290, 2010.

HOFFMANN, F. S.; SANTOS, G. DOS; MORELLI, M. R. Estudo de fundente e argilito com potencial para uso em formulações de porcelanato. Cerâmica, v. 58, p. 174-185, 2012

LIMA, T. C.; SOUZA, M. M.; ALMEIDA, A. B. D.; FARIAS, D. S. U.; NÓBREGA, L. F. P. M.; MENDES, L. B. Aplicação de resíduos de gipsita em formulações de massas cerâmicas. In: $22^{\circ}$ Congresso Brasileiro de Engenharia e Ciência dos Materiais (CBECiMat), Natal - RN, 2016.

MILE, M.; MITKOVA, T. Soil Moisture Retention Changes in Terms of Mineralogical Composition of Clays Phase. In: Clay Minerals in Nature - Their Characterization, Modification and Application Many. InTech, p. 101-118, 2012.

MONTEIRO, C. M. O. L.; NASCIMENTO, R. M.; MARTINELLI, A. E. Influência da Gipsita no Surgimento de Eflorescência em Telhas Cerâmicas. Cerâmica Industrial, v. 14, n. 4, p. 35-40, 2009.

OliveIRA, M. A. C.; SHINOHARA, A. H. A experiência com gás natural/GLP no polo gesseiro do Araripe, PE. Cerâmica, v. 60, p. 243-253, 2014.

SOUZA, C. C. I.; VIEIRA, C. M. F.; MONTEIRO, S. N. Alterações microestruturais de cerâmica argilosa incorporada com rejeito de minério de ferro. Revista Matéria, v. 13, n. 1, p. 194-202, 2008.

TEIXEIRA-NETO, É.; TEIXEIRA-NETO, Â. A. Modificação química de argilas: desafios científicos e tecnológicos para obtenção de novos produtos com maior valor agregado. Química Nova, v. 32, n. 3, p. 809-817, 2009.

VIEIRA, C. M. F.; EMILIANO, J. V. Incorporação de pó de rocha sedimentar em massas para telhas cerâmicas Parte 1 : Efeitos nas propriedades físicas e mecânicas. Cerâmica, v. 59, p. 389-394, 2013.

VIEIRA, C. M. F.; MONTEIRO, S. N. Influência da temperatura de queima na microestrutura de argilas de Campos dos Goytacazes-RJ. Cerâmica, v. 49, p. 6-10, 2003.

VIEIRA, C. M. F.; PINHEIRO, R. M. Incorporação de rocha sedimentar em pó em massas para telhas cerâmicas Parte 2 : avaliação microestrutural. Cerâmica, v. 59, p. 495-500, 2013.

VITORINO, A. C. T.; FERREIRA, M. M.; CURI, N.; LIMA, J. M.; SILVA, M. L. N.; MOTTA, P. E. F. Mineralogia, química e estabilidade de agregados do tamanho de silte de solos da Região Sudeste do Brasil. Pesquisa Agropecuária Brasileira, v. 38, n. 1, p. 133-141, 2003. 